\title{
Pre-End-Stage Renal Disease Care Not Associated with Dialysis Facility Neighborhood Poverty in the United States
}

\author{
Laura C. Plantinga ${ }^{a, b} \quad$ Min Kim $^{a, b} \quad$ Margarethe Goetz ${ }^{a, b} \quad$ David G. Kleinbaum ${ }^{a}$ \\ William McClellan ${ }^{a, c}$ Rachel E. Patzer ${ }^{a, d}$ \\ a Department of Epidemiology, Rollins School of Public Health, ${ }^{b}$ Laney Graduate School, ' Division of Nephrology, \\ Department of Medicine, and ${ }^{\mathrm{d}}$ Division of Transplantation, Department of Surgery, Emory University School of \\ Medicine, Emory University, Atlanta, Ga., USA
}

\section{Key Words}

Neighborhood · Poverty · End-stage renal disease ·

Access to care

\begin{abstract}
Background: Receipt of nephrology care prior to end-stage renal disease (ESRD) is a strong predictor of decreased mortality and morbidity, and neighborhood poverty may influence access to care. Our objective was to examine whether neighborhood poverty is associated with lack of pre-ESRD care at dialysis facilities. Methods: In a multi-level ecological study using geospatially linked 2007-2010 Dialysis Facility Report and 2006-2010 American Community Survey data, we examined whether high neighborhood poverty ( $\geq 20 \%$ of households in census tract living below poverty) was associated with dialysis facility-level lack of pre-ESRD care (percentage of patients with no nephrology care prior to dialysis start) in mixed-effects models, adjusting for facility and neighborhood confounders and allowing for neighborhood and regional random effects. Results: Among the 5,184 facilities examined, 1,778 (34.3\%) were located in a high-poverty area. Lack of pre-ESRD care was similar in poverty areas (30.8\%) and other neighborhoods (29.6\%). With adjustment, the absolute increase in percentage of patients at a facility with no pre-ESRD care associated with facility location in a
\end{abstract}

poverty area versus other neighborhood was only $0.08 \%$ $(95 \% \mathrm{Cl}-1.32,1.47 ; \mathrm{p}=0.9)$. Potential effect modification by race and income inequality was detected. Conclusion: Despite previously reported detrimental effects of neighborhood poverty on health, facility neighborhood poverty was not associated with receipt of pre-ESRD care, suggesting no need to target interventions to increase access to pre-ESRD care at facilities in poorer geographic areas.

(c) 2014 S. Karger AG, Base

\section{Introduction}

Annually, more than 100,000 individuals in the United States initiate treatment for end-stage renal disease (ESRD) [1]. Among these individuals, receipt of nephrology care prior to ESRD is a strong predictor of better dialysis preparedness [2-4], access to the transplant waiting list [5], and survival [6-10]. Despite these benefits, more than one third (34\%) of US ESRD patients begin dialysis treatment not having seen a nephrologist [1], and facilities with high proportions of such patients have worse facility-level mortality rates. The prevalence

M. Kim and M. Goetz contributed equally to this work.

\section{KARGER}

E-Mail karger@karger.com

www.karger.com/ajn
(C) 2014 S. Karger AG, Basel

0250-8095/14/0391-0050\$39.50/0
Laura Plantinga, ScM

Department of Epidemiology, Rollins School of Public Health

Claudia Nance Rollins Building, 3rd Floor

1518 Clifton Road NE, Atlanta, GA 30322 (USA)

E-Mail laura.plantinga@emory.edu 
of centers with low rates of pre-ESRD care varies geographically, with clusters of such centers within poorer areas [11]. This clustering suggests that there may be regional correlates of receipt of pre-ESRD care - particularly neighborhood socioeconomic factors that may influence access to care or care received prior to start of ESRD treatment at a facility. Further, the socioeconomic status of neighborhood of the dialysis facility itself likely influences the composition of its patient population. Patients who seek ESRD care at facilities in lowsocioeconomic status neighborhoods may be more limited in their choices than other ESRD patients, which may be associated with an underlying general lack of access to medical care.

There have been few studies that have examined the role of community poverty on quality of care in ESRD treatment centers. Our objective was to examine, in a multi-level ecological study, whether poverty in dialysis facility neighborhoods is associated with lack of nephrology care prior to initiating dialysis at the facility.

\section{Methods}

\section{Data}

Sources. Two national, publicly available datasets, linked geospatially by the locations of dialysis facilities, comprised our data. First, the 2007-2010 Dialysis Facility Report (DFR) provided data on the percentage of patients who have not received any pre-ESRD care, as well as on sociodemographic and clinical variables at the level of the dialysis facility and the ESRD network. DFR data are reported annually by the University of Michigan Kidney Epidemiology and Cost Center under a contract with the Centers for Medicare \& Medicaid Services (CMS), which covers all ESRD treatment in the United States (for those eligible for social security benefits), regardless of age or disability status. Second, the 2006-2010 American Community Survey (ACS) provided data from randomly sampled questionnaires on socioeconomic variables at the level of the census tract, as a proxy for neighborhood. ACS data are collected annually by the US Census Bureau and are aggregated over years and geographic regions to decrease potential identifiability and effects of random variation.

Geocoding. Addresses of all US dialysis facilities were geocoded, and the resulting coordinates were spatially joined with US 2010 census tract shapefiles. Of a total of 5,713 dialysis facilities in the United States (excluding Puerto Rico), 5,614 (98.3\%) were successfully geocoded and matched to a census tract. Of these, 370 facilities were not found in the DFR data, leaving 5,244 facilities $(91.8 \%$ of all US facilities) with complete information, representing 4,840 US neighborhoods and all 18 ESRD networks.

Outcome Variable. Facility-level lack of pre-ESRD care, from the DFR data, was defined by the percentage of patients at a facility in 2010 whose Medicare eligibility forms indicated no nephrology referral prior to initiation of dialysis (i.e. a response of 'no' on the item 'Prior to ESRD therapy: was patient under care of a nephrologist?'). The variable was primarily analyzed as a linear con- tinuous variable with a range of $0-100 \%$. A total of 60 facilities (1.1\% of matching facilities) were missing information on facilitylevel lack of pre-ESRD care and excluded from main analyses, leaving 5,184 facilities in the analysis.

Exposure Variable. Neighborhood-level poverty, from the ACS data, was defined by the percentage of households in a census tract living below $100 \%$ of the federal poverty threshold (as defined in the survey year; for example, in 2010, the threshold was USD 22,314 for a family of four). This variable was dichotomized at $\geq 20 \%$ tract-level poverty per the US Census Bureau definition of a 'poverty area' [12].

Potential Confounders. At the dialysis facility level, mean age, percentage of population that reported Black race, percentage with no insurance prior to ESRD start, and mean number of comorbid conditions were considered as possible confounders. At the neighborhood level the Gini index of income inequality (range $0-1$, with 1 = greatest inequality between highest and lowest income) [13] and percentage of the population that reported Black race were considered as potential confounders. All variables that represented percentages were analyzed in $+10 \%$ absolute increments for ease of interpretation. The Gini index was similarly analyzed in increments of +0.1 .

Potential Effect Modifiers. We hypothesized that the level of income inequality (as measured by the Gini index) and the percentage of the population that reported Black race, both at the neighborhood level, might modify the association between neighborhood-level poverty and lack of pre-ESRD care at the facility level. Thus, interaction terms were included in all initial models to assess this potential effect modification.

\section{Statistics}

Main Analyses. Dialysis facility and neighborhood characteristics were described and compared to overall US facility and neighborhood characteristics. Mixed-effects, multi-level linear models, with random effects at the network and neighborhood levels, were used to assess the association between neighborhood-level poverty $(\geq 20$ vs. $<20 \%)$ and lack of pre-ESRD care. Random effects were tested for statistical significance with mixture tests. Fixed factors that were found to be collinear by assessment of variance decomposition proportions and condition indices were removed. Likelihood ratio tests were used to test the statistical significance of prespecified interaction terms. Confounding was assessed with backward elimination of all variables from the model that resulted in a $<10 \%$ change in the estimate. Robust variance techniques were used to account for the possible failure of the assumption of conditional independent covariance structure. Statistical significance was set at $\mathrm{p}<0.05$. SAS v. 9.3 (SAS Institute, Cary, N.C., USA) and Stata v. 11 (StataCorp, College Station, Tex., USA) used for analysis and data management. Geocoding, spatial joining, and mapping were performed using ArcMap v. 10.1 (ESRI, Redlands, Calif., USA).

Sensitivity Analyses. All analyses were performed as above, but with (1) neighborhood poverty as a continuous variable, in $+10 \%$ absolute increments, (2) neighborhood poverty in quintiles, and (3) pre-ESRD care dichotomized at $\geq 30 \%$ versus $<30 \%$ (the median value), using generalized linear mixed models with a binomial distribution and logit link. These analyses were performed to test the robustness of the results to our assumptions that neighborhood poverty has a meaningful cutoff at 20\% (1 and 2) and preESRD care has a linear association with poverty (2 and 3 ). 


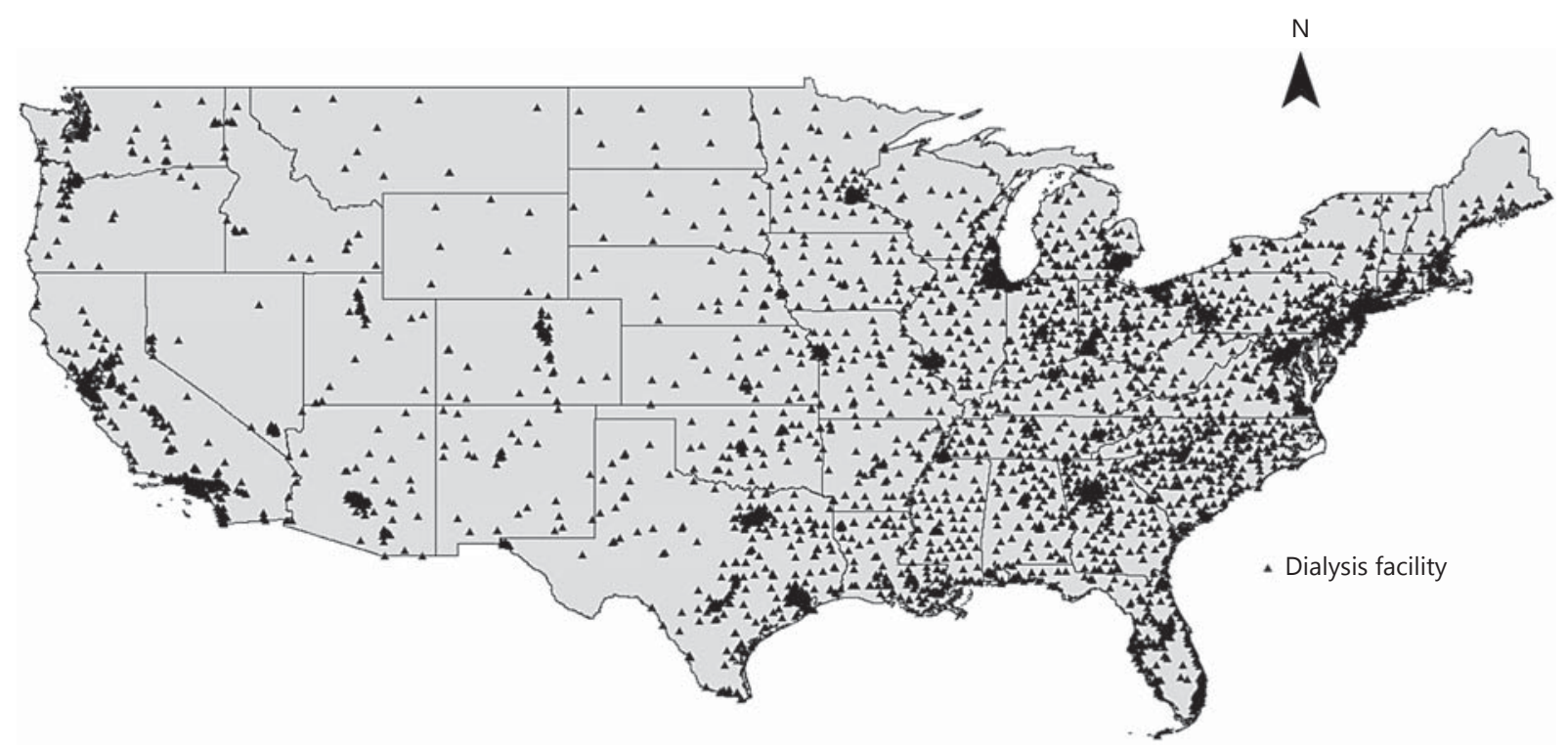

Source: 2007 - 2010 Dialysis Facility Report, Centers for Medicaid and Medicare Services

Fig. 1. Geographic distribution of 5,184 US dialysis facilities reporting level of pre-ESRD care among their patients

Table 1. US dialysis facility and neighborhood characteristics, by neighborhood poverty, DFR 2007-2010 and ACS 2006-2010

\begin{tabular}{|c|c|c|c|c|}
\hline Characteristics & \multicolumn{3}{|c|}{ Neighborhoods with dialysis facilities } & $\begin{array}{l}\text { All US neighbor- } \\
\text { hoods (from ACS } \\
2006-2010 \text { only) }\end{array}$ \\
\hline \multicolumn{5}{|c|}{ Characteristics of facilities by neighborhood poverty } \\
\hline Mean age & $61.6(7.7)$ & $64.2(7.3)$ & $63.3(7.5)$ & \\
\hline$\%$ no insurance & $9.4(12.2)$ & $6.3(8.9)$ & $7.3(10.3)$ & \\
\hline No. of comorbid conditions & $3.1(0.9)$ & $3.1(0.9)$ & $3.1(0.9)$ & \\
\hline$\%$ no pre-ESRD care & $30.8(21.6)$ & $29.6(20.8)$ & $29.9(21.1)$ & \\
\hline \multicolumn{5}{|c|}{ Characteristics of neighborhoods by neighborhood poverty } \\
\hline$\%$ poverty & $31.0(10.2)$ & $10.1(5.1)$ & $17.3(12.3)$ & $14.8(12.3)$ \\
\hline$\%$ Black & $30.6(29.5)$ & $11.9(18.6)$ & $18.3(24.6)$ & $13.6(22.6)$ \\
\hline$\%$ public assistance & $21.7(10.8)$ & $8.0(5.7)$ & $12.7(10.2)$ & $10.9(10.4)$ \\
\hline
\end{tabular}

Data are presented as means with SD in parentheses. $\%$ Black $=$ percentage of patients (facility) and population (neighborhood) reporting Black race; $\%$ female $=$ percentage of patients at facility who are female; \% no insurance = percentage of patients reporting no insurance before the start of ESRD treatment; \% no pre-ESRD care $=$ percentage of patients having no nephrology visits prior to the start of ESRD treatment; \% poverty = percentage of households reporting income $<100 \%$ federal poverty threshold; Gini index $=$ Gini index of income inequality; \% unemployed = percentage of population $15+$ reporting being in labor market but unemployed; $\%$ high-school graduates $=$ percentage of population $25+$ reporting being high school graduates or equivalent; \% owned housing = percentage of housing that is owned; $\%$ public assistance = percentage of households reporting receipt of any public assistance. 


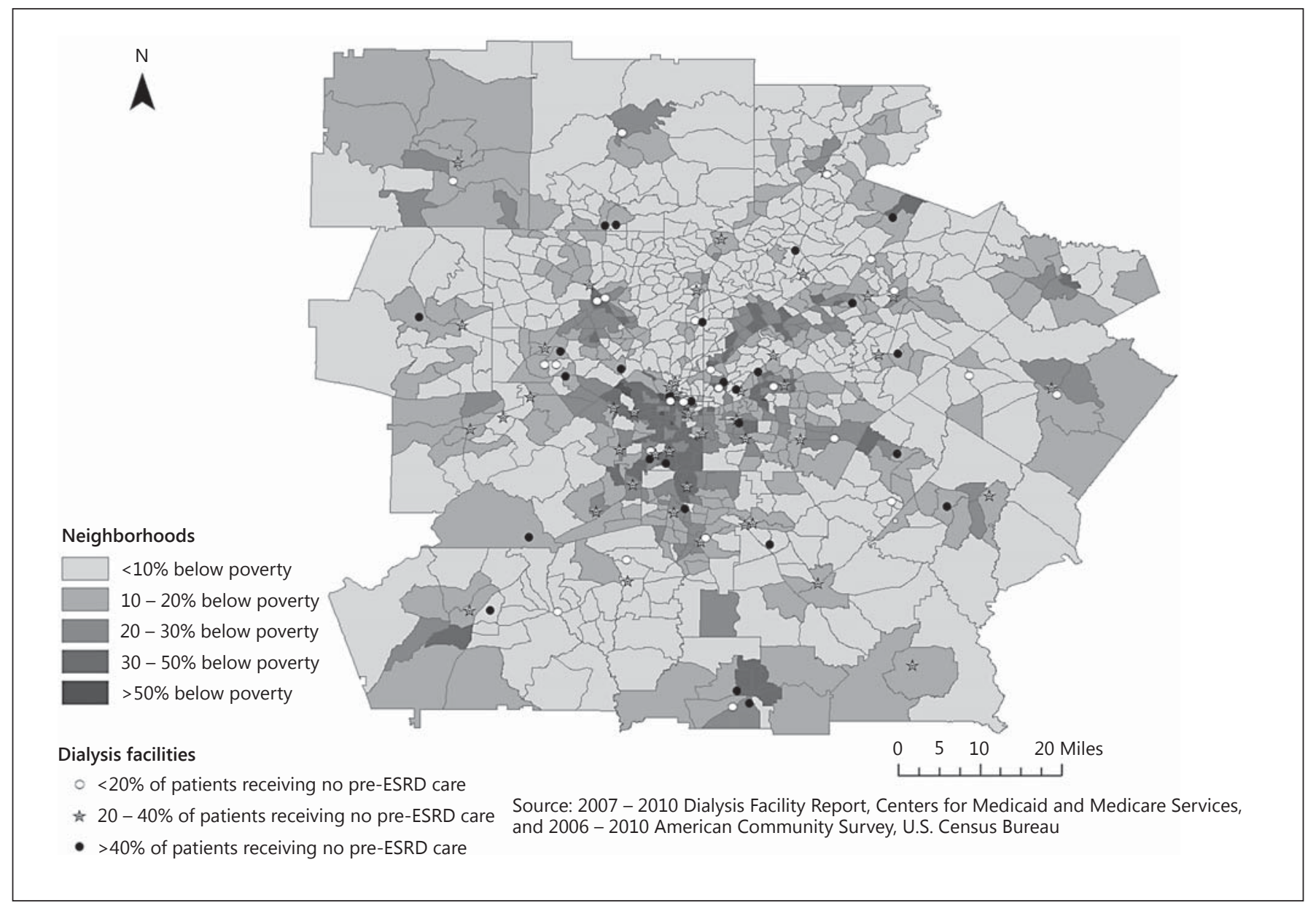

Fig. 2. Distribution of dialysis facility-level lack of pre-ESRD care by neighborhood poverty in the Atlanta, Ga., metropolitan statistical area. Symbols at dialysis facility locations represent lack of pre-ESRD care: low ( $<20 \%$ of patients, open circles), middle ( $20-40 \%$ of patients, stars), and high ( $>40 \%$ of patients, filled circles).

\section{Results}

Dialysis Facility and Neighborhood Characteristics

Among 5,184 US dialysis facilities examined, which were clustered in the South, Northeast, and West, as well as around urban areas (fig. 1), 1,778 (34.3\%) were located in neighborhoods considered 'poverty areas' (high neighborhood-level poverty, defined as $\geq 20 \%$ ). Table 1 shows that the dialysis facilities located in neighborhoods designated as poverty areas had a lower mean age and higher percentage of Black patients and patients without insurance at the start of ESRD treatment, relative to facilities in neighborhoods that had less poverty. Notably, the mean percentage of patients in a facility receiving no pre-ESRD care did not differ by whether neighborhoods were designated poverty areas (30.8 vs. $29.6 \%$; table 1). Dialysis facility neighborhoods that were considered poverty areas, compared to neighborhoods not considered poverty areas, had greater percentages of residents who were Black, unemployed, or using public assistance; a lower percentage of highschool graduates and homeowners, and a higher Gini index of income inequality. Additionally, relative to the overall US neighborhood average, neighborhoods with dialysis facilities had greater levels of poverty (17.3 vs. $14.8 \%)$ and a greater percentage of Black residents (18.3 vs. $13.6 \%$; table 1). The 370 facilities excluded due to missing DFR data had similar percentages of households living below poverty (17.3\%), Black residents (18.0\%), and high-school graduates (84.5\%) and a similar Gini index (0.42), compared to the included facilities. 
Table 2. Association of US dialysis facility neighborhood poverty with facility-level lack of pre-ESRD

\begin{tabular}{|c|c|c|c|}
\hline Analysis* & \multicolumn{2}{|c|}{ Stratification levels** } & Estimate $(95 \% \mathrm{CI})$ \\
\hline$\geq 20$ vs. $<20 \%$ poverty & - & - & $0.08(-1.32,1.47)$ \\
\hline \multicolumn{3}{|c|}{ B Sensitivity analysis: continuous poverty, continuous lack of pre-ESRD care } & $\beta$ \\
\hline Low vs. no poverty & low & - & $0.77(0.23,1.30)$ \\
\hline High vs. no poverty & high & - & $0.66(-0.49,1.82)$ \\
\hline \multicolumn{3}{|c|}{ C Sensitivity analysis: poverty in quintiles, continuous lack of pre-ESRD care } & $\beta$ \\
\hline \multicolumn{3}{|c|}{ Quintile 2 vs. 1} & $2.48(0.69-4.27)$ \\
\hline \multicolumn{3}{|l|}{ Quintile 3 vs. 1} & $2.82(0.99-4.65)$ \\
\hline \multicolumn{3}{|l|}{ Quintile 4 vs. 1} & $1.93(0.02-3.84)$ \\
\hline \multirow[t]{2}{*}{ High vs. no poverty } & - & low & $1.18(1.08,1.29)$ \\
\hline & - & high & $1.11(1.02,1.21)$ \\
\hline
\end{tabular}

* Main analysis (A): Adjusted for percentage Black (facilityand neighborhood-level), percentage with no insurance (facilitylevel), mean number of comorbid conditions (facility-level), and Gini index (neighborhood-level) and including random intercepts at the network and neighborhood level and random slope for percentage Black at the facility level. Interactions for poverty*Black and poverty* Gini index at the neighborhood level were not statistically significant and no stratifications are shown.

Sensitivity analysis (B): Adjusted for percentage Black (facilityand neighborhood-level), percentage with no insurance (facilitylevel), mean number of comorbid conditions (facility-level), and Gini index (neighborhood-level) and including random intercept at the neighborhood level. Interaction for poverty*Black at the neighborhood level was not statistically significant, but poverty* Gini index was statistically significant and estimates are shown stratified by Gini index. Low and high poverty represent 33 rd and 66th percentiles, respectively: 9.8 and $20.4 \%$.
Sensitivity analysis (C): Adjusted for percentage Black (facilityand neighborhood-level), percentage with no insurance (facilitylevel), mean number of comorbid conditions (facility-level), and Gini index (neighborhood-level) and including random intercepts at the network and neighborhood level and random slope for percentage Black at the facility level.

Sensitivity analysis (D): Adjusted for percentage Black (neighborhood-level) only (no other potential confounders remained after backward elimination) including random intercept at the neighborhood level. Interaction for poverty* Gini at the neighborhood level was not statistically significant, but poverty*Black was statistically significant and estimates are shown stratified by percentage Black at the neighborhood level. Low and high poverty represent 33rd and 66th percentiles, respectively: 9.8 and $20.4 \%$.

** Low and high levels of stratifiers represent 33rd and 66th percentiles, respectively: Gini index 0.39 and 0.45 ; \% Black 2.6 and $16.0 \%$.

\section{Association of Dialysis Facility and Neighborhood} Characteristics with Facility-Level Pre-ESRD Care

The crude association - not accounting for geographic hierarchy of the data - between neighborhood poverty and facility-level lack of pre-ESRD care is shown in the online supplementary figure (for all online suppl. material, see www.karger.com/doi/10.1159/000358067). A statistically significant but quite modest association was seen $(\beta=0.07, p=0.003)$. Figure 2 shows facility-level lack of pre-ESRD care by neighborhood poverty in the Atlanta, Georgia, metropolitan statistical area (fig. 2). The map shows that there was no clear pattern in this small geographic area (which may not reflect national patterns): facilities with relatively high and low levels of lack of preESRD care were scattered throughout neighborhoods of both high- and low-poverty levels (fig. 2).

In multi-level multivariable-adjusted models with the national data, allowing for random effects at the neighborhood and ESRD network levels, the association of neighborhood poverty with lack of pre-ESRD care at the facility level remained essentially null (table 2 , analysis A). The absolute change in the percentage of patients at the facility having no pre-ESRD care associated with a facility being located within a neighborhood considered a poverty area, versus within a non-poverty area neighborhood, was only $0.08 \%$. This association was not statistically significant 
( $p=0.9$ by Wald test). Neither of the interactions of neighborhood poverty (with the Gini index or percentage Black race) was statistically significant in the main analyses. Neither excluding facility-level insurance nor including facility size in the models gave substantially different results.

In contrast, sensitivity analyses gave some statistically significant, but modest, results. When neighborhood poverty was examined as a continuous variable, the interaction of poverty and the Gini index was statistically significant; thus, results are shown stratified by Gini index levels, at low and high levels of poverty (table 2, analysis B). Within neighborhoods with lower levels of income inequality, low and high (vs. no) poverty increased the percentage of patients who did not receive any pre-ESRD care by 0.8 and $1.6 \%$, respectively. Within neighborhoods with higher levels of income inequality, the respective changes in lack of pre-ESRD care were 0.3 and $0.7 \%$, but the estimates were not statistically significant (table 2, analysis B). All quintiles of neighborhood poverty were associated with modestly higher levels of pre-ESRD care, relative to the lowest quintile (table 2 , analysis $C$ ). In the third set of sensitivity analyses, in which lack of pre-ESRD care was dichotomized (table 2, analysis D), higher and lower levels of poverty (vs. no poverty) increased the odds of $>30 \%$ of patients lacking pre-ESRD care at the facility level by 8 and 18\%, respectively, within neighborhoods with lower percentages of Black residents. Within neighborhoods with higher percentages of Black residents, the respective changes in odds of $>30 \%$ of patients lacking pre-ESRD care were 5 and $11 \%$ (table 2, analysis D).

Analysis of covariance showed that contributions of random terms to the overall variance were modest: 2.4 and $2.1 \%$ for the network- and neighborhood-level intercepts, respectively. However, several of the network-level intercepts were statistically significant: ESRD networks 1 (New England) and 6 (Southeast) had significantly lower (5\% lower in absolute terms for both) baseline facility-level percentage of patients with no pre-ESRD care. In contrast, ESRD networks 12 (Midwest) and 13 (Central South) had significantly higher (3 and 6\% higher in absolute terms, respectively) baseline facility-level percentage of patients with no pre-ESRD care (see online suppl. table).

\section{Discussion}

We found that the association of dialysis facility location in a neighborhood considered a high-poverty area [12] with the percentage of patients with no pre-ESRD care was neither statistically nor clinically significant.

Neighborhood Poverty and Pre-ESRD

Care
Further, although some results were statistically significant, even large changes in poverty level resulted in very small changes in lack of pre-ESRD care. And while these associations of poverty with pre-ESRD care differed by strata of neighborhood-level income inequality in these sensitivity analyses, the magnitude of this possible effect modification was modest. Similarly, analyses with dichotomized pre-ESRD care showed a statistically but likely not clinically significant effect modification by neighborhood-level Black race.

It is well-established that the poor, particularly poor minorities, are disproportionately affected by chronic kidney disease and ESRD [14-20]. Lower individual socioeconomic status has been associated with less access to kidney transplantation [21], lower graft survival [22], and decreased survival on hemodialysis [23]. While less well studied, there is also evidence from large US cohort studies that areal poverty is also associated with increased risk of chronic kidney disease, independent of individual poverty status $[24,25]$ - although this evidence is inconsistent [26] - and that residential neighborhood poverty is strongly associated with increased risk of ESRD [27]. Additionally, neighborhood poverty has been associated with decreased chance of kidney transplantation and waitlisting $[28,29]$, suggesting that access to other types of kidney disease care may be inversely associated with neighborhood poverty. Given these known disparities and the importance of pre-ESRD care in decreasing risk of mortality after the start of ESRD treatment $[11,30]$, it is crucial that pre-ESRD care be at least as accessible to those living in, or seeking treatment in, neighborhoods that are relatively poor, as it is to patients in relatively wealthy neighborhoods.

In this study, we found no clinically significant association between facility neighborhood poverty and facility-level pre-ESRD care. These results may reflect an underlying truth that there is either no or only a very modest association of facility neighborhood poverty with the proportion of patients at a facility who receive no pre-ESRD care. This would suggest that all patients might benefit from interventions to increase pre-ESRD care among those with chronic kidney disease, and that interventions would not necessarily be more effective if they were targeted at particular geographic areas.

There are also other possible explanations for our results. We focused on the neighborhood of the dialysis facility. This approach is novel in the sense that it allows examination of geographic effects beyond the residential neighborhood. However, particularly since pre-ESRD care is sought outside of dialysis clinics, poverty in neigh- 
borhoods where patients spend the majority of time prior to ESRD may affect access to pre-ESRD care more strongly. Our data suggested that dialysis facilities tend to be located in neighborhoods with worse socioeconomic status than the US average neighborhood, so it is possible that the neighborhood where the patient sought health care prior to ESRD would have a different poverty status than that of their eventual dialysis facility. Indeed, dialysis facilities that serve higher socioeconomic status patients may choose poorer neighborhoods to keep operating costs low. Additionally, patients with greater resources may choose their facilities based on quality factors, whereas those with fewer resources, particularly those who need CMS benefits for transportation - which covers only the nearest facility to patient residence - may have little to no choice in dialysis facility. Further, those with the fewest resources (such as those who are not Medicare-eligible) may receive their care in emergency rooms or safety net hospitals, and such patients are not included here. Patients who do receive pre-ESRD care are likely to choose the facility to which they are referred by their nephrologist, and the neighborhood of chosen eventual facility may differ from that where they reside.

Another reason that these results may not be consistent with prior studies of the effects of neighborhood poverty on consequences and treatment of kidney disease relates to differing definitions of neighborhood and poverty. For example, the geospatial concentration of poverty, which takes into account poverty in a single area as well as the poverty of surrounding areas [31], may have more influence on pre-ESRD care than the socioeconomic status of the neighborhood of the dialysis facility alone. McClellan et al. [32] found that facility-level prevalence of arteriovenous fistula use - a marker of quality preESRD care - was inversely associated with concentration of poverty, defined at the county level. Additionally, many previous studies of neighborhood and kidney disease have used zip code-defined areas. These areas are less likely to be relevant to health than areas defined by census tracts, which, at least initially, are 'designed to be homogeneous with respect to population characteristics, economic status, and living conditions' (http://www.census. gov/geo/www/geo_defn.html) and have been shown not to predict outcomes as well as census tracts in health studies [33]. However, even with census tracts, the true impact on estimated effects by how neighborhood boundaries are drawn (the 'modifiable areal unit problem') remains unknown [34, 35]. In fact, it has suggested that any administrative set of boundaries is unlikely to capture neighborhoods as residents perceive them [36]. Thus, census tracts are likely imperfect proxies of neighborhoods, and the direction of any potential bias due to this issue is unclear. Additionally, cumulative lifetime effects of neighborhood poverty, which could not be captured here, could influence access to and seeking of care.

We also found that there are likely differences in baseline values of lack of pre-ESRD care at the facility level across ESRD networks, regardless of any associations with neighborhood poverty. New England and the Southeast (the Carolinas and Georgia) had higher baseline levels of pre-ESRD care, whereas the Midwest and Central South had lower levels, relative to other networks. Previous studies on geographic variation in pre-ESRD care have focused on rurality of residence and have found either no substantial differences [37] or diminished preESRD care in urban and rural areas, relative to suburban areas [38]. Particularly for the Southeast, our results were somewhat surprising, given these states' somewhat poorer performance in other areas of kidney disease treatment, compared to the rest of the nation, including transplantation rates [1] and achievement of guidelines for fistula placement [39]. These results suggest that, at least in this region, deficiencies in other aspects of quality of care may not be improved merely by improving access to preESRD care at the population or ESRD network level.

In addition to the limitations discussed above, several others warrant mention. First, this was an ecological study, which limits the interpretation of any observed association. Information on lack of pre-ESRD care did not include numbers of individuals, precluding a binary (events/trials) analysis, which may have produced different results. Thus, results and their interpretations should be considered hypothesis-generating rather than causal. This study design also prevented control of confounding at the individual level (for example, by individual age, race, poverty, and comorbid conditions). There is also potential misclassification of facility- and network-level variables due to variation in dialysis facility personnel reporting the data and due to smaller facilities having greater variation in denominator over time. However, the study also has several strengths. The potential for selection bias is limited (with only $1 \%$ of observations missing outcome data). Additionally, although 370 facilities $(<10 \%$ of all US facilities) were missing DFR data, these facilities did not differ from those included in the study by neighborhood characteristics. These data are also national and representative, including most of the dialysis facilities in the United States and, within these facilities, summarized variables based on all US citizens who are treated for ESRD.
Plantinga/Kim/Goetz/Kleinbaum/ McClellan/Patzer 
In conclusion, despite previously reported detrimental effects of neighborhood poverty on health, we found that dialysis facility neighborhood poverty was not associated with facility-level lack of pre-ESRD care in this multi-level, ecological study. The observed statistical interactions with the Gini index and race, while modest, suggest that homogeneity of neighborhood poverty and race as predictors of lack of pre-ESRD care may warrant further investigation. Additionally, unexpected geographic patterns in pre-ESRD care suggest that access to care may not be sufficient to improve quality of care and outcomes in ESRD.

\section{Acknowledgements}

We thank the University of Michigan Kidney Epidemiology and Cost Center for their assistance with data acquisition. These results were presented in part at the 2013 meeting of the American Society of Nephrology, held November 5-10, 2013, in Atlanta, Ga. R.E.P. was supported in part by grants from the National Center for Advancing Translational Sciences of the National Institutes of Health under award No. ULl TR000454 and KL2TR000455 and by R24MD008077 through the National Institute on Minority Health and Health Disparities. The content is solely the responsibility of the authors and does not necessarily represent the official views of the National Institutes of Health or the US Government.

\section{Disclosure Statement}

The authors have no conflicts of interest to disclose.

\section{References}

1 US Renal Data System, USRDS 2013 Annual Data Report: Atlas of End-Stage Renal Disease in the United States, National Institutes of Health, National Institute of Diabetes and Digestive and Kidney Diseases, Bethesda 2013.

-2 Astor BC, Eustace JA, Powe NR, Klag MJ, Sadler JH, Fink NE, et al: Timing of nephrologist referral and arteriovenous access use: the CHOICE Study. Am J Kidney Dis 2001;38 494-501.

-3 Avorn J, Winkelmayer WC, Bohn RL, Levin R, Glynn RJ, Levy E, et al: Delayed nephrologist referral and inadequate vascular access in patients with advanced chronic kidney failure. J Clin Epidemiol 2002;55:711-716.

-4 Winkelmayer WC, Glynn RJ, Levin R, Owen W Jr, Avorn J: Late referral and modality choice in end-stage renal disease. Kidney Int 2001;60:1547-1554.

5 Winkelmayer WC, Glynn RJ, Levin R, Mittleman MA, Pliskin JS, Avorn J: Late nephrologist referral and access to renal transplantation. Transplantation 2002;73:1918-23.

6 Winkelmayer WC, Owen WF Jr, Levin R, Avorn J: A propensity analysis of late versus early nephrologist referral and mortality on dialysis. J Am Soc Nephrol 2003;14:486-492.

7 Kinchen KS, Sadler J, Fink N, Brookmeyer R, Klag MJ, Levey AS, et al: The timing of specialist evaluation in chronic kidney disease and mortality. Ann Intern Med 2002;137: 479-486.

8 Stack AG: Impact of timing of nephrology referral and pre-ESRD care on mortality risk among new ESRD patients in the Unite States. Am J Kidney Dis 2003;41:310-318.
-9 Kazmi WH, Obrador GT, Khan SS, Pereira BJ, Kausz AT: Late nephrology referral and mortality among patients with end-stage renal disease: a propensity score analysis. Nephrol Dial Transplant 2004;19:1808-1814.

10 Hasegawa T, Bragg-Gresham JL, Yamazaki S, Fukuhara S, Akizawa T, Kleophas W, et al: Greater first-year survival on hemodialysis in facilities in which patients are provided earlier and more frequent pre-nephrology visits. Clin J Am Soc Nephrol 2009;4:595-602.

-11 McClellan WM, Wasse H, McClellan AC, Kipp A, Waller LA, Rocco MV: Treatment center and geographic variability in preESRD care associate with increased mortality. J Am Soc Nephrol 2009;20:1078-1085.

12 Bishaw A: Areas with concentrated poverty: 2006-2010. American Community Survey Briefs. Suitland/MD, US Census Bureau, December 2011.

13 Sen A, Foster JE: On Economic Inequality, expanded ed. Oxford, Clarendon Press, 1997.

14 Bruce MA, Beech BM, Crook ED, Sims M, Wyatt SB, Flessner MF, et al: Association of socioeconomic status and CKD among African-Americans: the Jackson Heart Study. Am J Kidney Dis 2010;55:1001-1008.

15 Crews DC, Charles RF, Evans MK, Zonderman AB, Powe NR: Poverty, race, and CKD in a racially and socioeconomically diverse urban population. Am J Kidney Dis 2010;55: 992-1000.

16 Hall YN, Choi AI, Chertow GM, Bindman $\mathrm{AB}$ : Chronic kidney disease in the urban poor. Clin J Am Soc Nephrol 2010;5:828-835.

17 Fored CM, Ejerblad E, Fryzek JP, Lambe M, Lindblad P, Nyren O, et al: Socio-economic status and chronic renal failure: a populationbased case-control study in Sweden. Nephrol Dial Transplant 2003;18:82-88.
18 White SL, McGeechan K, Jones M, Cass A, Chadban SJ, Polkinghorne KR, et al: Socioeconomic disadvantage and kidney disease in the United States, Australia, and Thailand. Am J Public Health 2008;98:1306-1313.

19 Hossain MP, Goyder EC, Rigby JE, El Nahas M: CKD and poverty: a growing global challenge. Am J Kidney Dis 2009;53:166-174.

20 Young BA: The interaction of race, poverty, and CKD. Am J Kidney Dis 2010;55:977-980.

21 Thamer M, Henderson SC, Ray NF, Rinehart CS, Greer JW, Danovitch GM: Unequal access to cadaveric kidney transplantation in California based on insurance status. Health Serv Res 1999;34:879-900.

22 Butkus DE, Dottes AL, Meydrech EF, Barber WH: Effect of poverty and other socioeconomic variables on renal allograft survival. Transplantation 2001;72:261-266.

23 McClellan WM, McClellan CB: Poverty and mortality in hemodialysis patients. J Am Soc Nephrol 2013;24:165-167.

24 Merkin SS, Coresh J, Roux AV, Taylor HA, Powe NR: Area socioeconomic status and progressive CKD: the Atherosclerosis Risk in Communities (ARIC) Study. Am J Kidney Dis 2005;46:203-213.

25 Merkin SS, Diez Roux AV, Coresh J, Fried LF, Jackson SA, Powe NR: Individual and neighborhood socioeconomic status and progressive chronic kidney disease in an elderly population: The Cardiovascular Health Study. Soc Sci Med 2007;65:809-821.

-26 McClellan WM, Newsome BB, McClure LA, Howard G, Volkova N, Audhya P, et al: Poverty and racial disparities in kidney disease: the REGARDS study. Am J Nephrol 2010;32: $38-46$. 
27 Volkova N, McClellan W, Klein M, Flanders D, Kleinbaum D, Soucie JM, et al: Neighborhood poverty and racial differences in ESRD incidence. J Am Soc Nephrol 2008;19:356364.

28 Patzer RE, Amaral S, Wasse H, Volkova N, Kleinbaum D, McClellan WM: Neighborhood poverty and racial disparities in kidney transplant waitlisting. J Am Soc Nephrol 2009;20:1333-1340.

29 Hall YN, O’Hare AM, Young BA, Boyko EJ, Chertow GM: Neighborhood poverty and kidney transplantation among US Asians and Pacific Islanders with end-stage renal disease. Am J Transplant 2008;8:2402-2409.

- 30 Kanda E, Erickson K, Bond TC, Krisher J, McClellan WM: Hemodialysis treatment center early mortality rates for incident hemodialysis patients are associated with the quality of care prior to starting but not following onset of dialysis. Am J Nephrol 2011;33:390-397.
31 Holt JB: The topography of poverty in the United States: a spatial analysis using countylevel data from the Community Health Status Indicators project. Prev Chronic Dis 2007; 4:A111.

32 McClellan WM, Wasse H, McClellan AC, Holt J, Krisher J, Waller LA: Geographic concentration of poverty and arteriovenous fistula use among ESRD patients. J Am Soc Nephrol 2010;21:1776-1782.

33 Krieger N, Chen JT, Waterman PD, Soobader MJ, Subramanian SV, Carson R: Geocoding and monitoring of US socioeconomic inequalities in mortality and cancer incidence: does the choice of area-based measure and geographic level matter? The Public Health Disparities Geocoding Project. Am J Epidemiol 2002;156:471-482.

34 Stafford M, Duke-Williams O, Shelton N: Small area inequalities in health: are we underestimating them? Soc Sci Med 2008;67: 891-899.
35 Flowerdew R, Manley DJ, Sabel CE: Neighbourhood effects on health: does it matter where you draw the boundaries? Soc Sci Med 2008;66:1241-1255.

- 36 Haynes R, Daras K, Reading R, Jones A: Modifiable neighbourhood units, zone design and residents' perceptions. Health Place 2007;13: 812-825.

37 Maripuri S, Ikizler TA, Cavanaugh KL: Prevalence of pre-end-stage renal disease care and associated outcomes among urban, micropolitan, and rural dialysis patients. Am J Nephrol 2013;37:274-280.

38 Yan G, Cheung AK, Ma JZ, Yu AJ, Greene T, Oliver $\mathrm{MN}$, et al: The associations between race and geographic area and quality-of-care indicators in patients approaching ESRD. Clin J Am Soc Nephrol 2013;8:610-618.

39 Lynch JR, Mohan S, McClellan WM: Achieving the goal: results from the Fistula First Breakthrough Initiative. Curr Opin Nephrol Hypertens 2011;20:583-592. 